\title{
Passionarity management: adapting the model to modern conditions
}

\author{
Yulia Karpovich ${ }^{1}$, and Natalya Pazdnikova ${ }^{{ }^{*}}$ \\ ${ }^{1}$ PNIPU, 29, Komsomolsky ave., Perm, 614990, Russia
}

\begin{abstract}
Public administration is now quite often identified with state and municipal administration, while the sign of identity between these concepts cannot be put, since public administration is the result of the development of state and municipal administration, its "higher stage of evolution". The article describes the situations when traditional ways of public management do not work that requires the development of qualitatively new methods of management or adoption of already developed once to the current conditions. The article is aimed to show the need to study the peculiarities of passionarity management as a perspective trend of public management. The authors analyze the existing theories in the field of passionarity management. The authors 'conclusions support the fact that the effectiveness of public management could be determined by the level of management passionarity.
\end{abstract}

\section{Introduction}

The changes taking place in the culture could be revealed through the process of creation new institutions, as well as new values in the modern society. While the economy undertakes the globalization trends year by year, the cultural capital is also growing and accumulated, creating different social forms.

Each era has its own effective management models. However, with the change of management paradigms, the approaches to choosing the most effective management tools also change. With the increasing complexity of public relations, those managers whose leadership and business qualities surpassed those of average managers, the most widespread and widespread, are beginning to play an increasingly important role [1].

In modern conditions, the need for a new quality of territorial management subjects that strive to form a high competitive tone and economic stability of the region in the long term is becoming increasingly clear. The existing scientific and practical approaches, which describe the formation of a new kind of relations in the public administration field, do not meet the requirements of large-scale and continuous social and economic innovations, as regards the expanded reproduction of new corporate knowledge.

The successfully implemented local initiatives have been as a rule indigenously trigged and directed to mobilization of local resources, diversification of different types of economic activity, introduction of new products on the market, improving skills and creation of new organizational forms for these activities.

Nowadays the intelligentsia as a social class, due to its weakness, cannot influence either social development or the economic ones. It has not still sought participation in contests for elected government positions, and it happens not due to the lack of money required for the participation, but because of uncertainty about achieving success. The same reason prevents this class from taking part in the struggle for power, although it is scientific class who could scientifically justify economic and political decisions, describe the best alternative variants and possible final result. The problems of the effectiveness of public administration in the regions actualize the issues of developing new approaches and tools in the management of territories. However, the search for and development of new tools and approaches is complicated by a number of factors, which should primarily include:

- terminological and conceptual uncertainty of the basic concepts of the control system[2];

- limited research on the nature and manifestation of passionarity in the field of public management.

\section{Literature review}

The problem of passionarity under the conditions of decreasing of creative activity of the personnel, already at the early stages of ontogenesis, has increasingly become the subject of scientific research recently. From a psychological standpoint, this problem is studied by V.Y. Bogdanov, who made a comparative analysis between the personal typology of L.M. Gumilyov and the psychological typology of character developed by K. Leongard. M. Kovalenko studied interconnections of passionarity, temperament and motivation [3]. K.G. Frumkin, tries to explain passionarity through the theory of sexuality by S. Freud (passionarity as manifestation of sublimated unconscious drives) etc.

Thus, Y. Beglov, the author of the information theory of thinking, proposes to determine passionarity from the standpoint of person's conscious understanding of their actions. "Passionarity is a predisposition to choose 
behaviors with poorly predicted effects instead of the well-predicted ones but with unsatisfactory after-effects. Such predisposition is the property of the current state of thinking which can be caused by innate features of the brain, evoked by behavior stereotypes and personal experience".

A broad definition of this term is given by modern dictionaries of foreign words, namely: passionary (from the Latin passio - suffering and even passivity, but also affect, passion; the one who possesses a higher activity, passion, whereas a passionarian (passion-filled) is an active person who has considerable inner energy. Derivatives in European languages differ in connotation. The British added a new meaning to passionarity: for them passion is an outbreak of anger; for the Poles it is rage, fury; passionant in Romanian is a person capable of carrying along and exciting others; for the Dutch, Danes, Germans and Swedes passion is just an excitement; in Ukrainian, the Latin passio is interpreted as passion (пристрасть). In everyday wide use, they call it any strong desire and even a weak drive. Thus, the etymology of this term, which is so polysemantic and diverse, is being specified. When appeared, this concept triggered various reactions in the scientific world: from admiration to hard criticism. Even in modern conditions the interpretation of the term has different variants in accordance with the authors' scientific preferences. For example, D.G. Davydov in his studies equates the concept of passionarity with the notion of vigorousness, proposed by M.P. Karpenko (from the English vigorous - active, cheerful, full of energy).

The great number of individual's actions is dictated by the instinct of self-preservation. Passionarity, on the other hand, has the opposite vector, as far as it perceives people to sacrifice themselves in the name of a great idea. When the aim of a person at the level of instinctive impulses to safe life is less than passionarity impulses, such a person is called a passionary one. As far as currently we have no instruments and methods of measuring the magnitude of passionarity, we can only talk about a tendency to increase or decrease a degree of passionarity.

Passionaries have a great potential of influencing the life of society. As it was proven by the historical facts society in different times could be in different states. If the society is in an equilibrium condition, there are no circumstances that are able to made a person to change his or her behavior, and no social imperatives are observed to strive voluntary death for the sake of their own aims. People with the abilities to be engaged in science and arts lead a quiet life build houses, cities. It's the time when harmonious individuals live in a stable society, feats and creative take-offs are valued, but there are only a few people capable to implement them in real life.

Using this assumption we can conclude that passionaries are ready to support society in a state of norm. It supposes that there is no passionary tension in the society. If any deviation happens, which leads to a situation when generally accepted imperative is viewed as something odious, society understood that it is in need of someone who will provide it an opportunity to survive and live in peace to the best of one's duties, and this idea is supported by the majority of the population.

When society is going through a time of serious reforms, involving the processes of creating a completely new social system, its passionarity of society is manifested in high level of public activity, which means the readiness of population for heroic deeds. In such a state, a part of society represents as much more than the whole. This is the elite of society, which could be called "the source of passionarity".

\section{Materials and methods}

Public management is characterized by a more extensive subject structure in comparison with state and municipal forms of government, since it involves the active participation of not only local authorities but also the population in the process of creating conditions for the balanced development of the territory. In this context, special attention should be paid to the special characteristics of proactive local representatives' community, who are able both to take an active part in the public administration and to involve other people in this process with the aim of raising the life quality of the population at the place in which they live [4, p.199].

The process of effective management is impossible without the development and implementation of new ways and methods of management, since the tools that previously gave tangible success lose their effectiveness over time and vice versa. Creativity in the public administration system is becoming more and more popular. The development of effective management tools involves the active use of the human factor, psychological and emotional aspects of motivation for making management decisions. After all, public administration is currently characterized by an active transformation of the sphere that adapts to changes in the external environment of the region, into a sphere that independently forms modern trends in regional development, which leads to a change in the nature of interaction between public administration bodies and the regional environment.

Such a characteristic feature of modern management can be reflected by a concept, introduced by $\mathrm{L}$. Gumilyov, as passionarity. According to his classical definition, passionarity is "the ability and desire to change the environment, or, translating into the language of physics, to break the inertia of the aggregate state of the environment" [5, p. 266]. The "passionate impulse of behaviour" is directed sometimes against the instinct of both individual and collective self-existence. It gives us the right to say that it has the vector that is opposite to basic instincts. Super-passionarity, according to $\mathrm{L}$. Gumilev, is the ability to reject personal needs for the sake of interests of one's nation, to make sacrifices for achieving highest national goals, collectivism, multiplied by heroism and working capacity.

Passionarity (in a broad sense), according to scientists, is an integrative characteristic of the personality whose qualities are directed towards selfimprovement and improvement of society and are based 
on the personality activity and have social significance: purposefulness, ability to overcome obstacles and ability to cope with overstrain; complementarity, leadership, adaptability, developed intuition, constructive aggressiveness and mature emotionality. However, it is quite natural that over time the meaning of the concept of passionarity has transformed and now its meaning differs from the one that was implied by L. M. Gumilyov.

It also happens that passionarity refers to the ability of a person (or group) to super-effort, super-tension, while the measure of passionarity is considered the relative number of such individuals in the society under consideration. In modern works, the manifestations of passionate behavior in relation to individuals, but not to society, are called vigor.

Passionarity is characterized by an exaggeration of the priority of the target settings, which reduces the obstacles that stand in the way of achieving them. This often explains the "revolutionary effectiveness" of management results, since this approach ignores traditional constraints, thereby expanding the boundaries of the search for new opportunities. The result of using this approach in management is management decisions of a fundamentally new quality level in comparison with the classical methods of public administration, which most fully take into account all existing limitations. Passionarity here manifests itself in the fact that the manager does not always manage to stay within the framework of rational decisions [6, p.18]. And public administration, as is well known, is not always based on the principles of economic efficiency, in some cases, social aspects prevail over cost (economic) ones.

\section{Results}

The researchers emphasize that the adaptive requirements of modern public administration call for leaders who take responsibility and do not expect that they will receive a revelation or instructions from higher management [7, p.192].

The transfer of the concept of passionarity from the plane of an individual to the sphere of public administration does not consist in a simple transfer of properties to a broader object, but in the special nature of their manifestation in such complex systems as public ones. This is due to the fact that in social systems, the self-organization of the individual is supplemented by social organization, since people acting in society are guided by their personal motives and values [8, p.67]. At the same time, the basis of leadership should be the process of interpersonal passionary influence that unfolds between the leader and the rest of the corporate community.

Thus, the formula of the ideal system of public administration in the logic of L. Gumilyov's ethnogenesis is as follows: "If a certain optimal ratio is established between the most important types of members of an ethnos - harmonious individuals (in whom passionarity and instinct are balanced) and passionaries (in whom passionarity is stronger than instinct) - the system is almost irresistible" [9, p.30].

L. Gumilev separated the society into two different groups of people:

1) Passionaries who could be described as charismatic and powerful people having their own clear vision about the future perspectives of the society development as well as the strong will to achieve goals. They are able to involve other individuals into action and strongly motivated at achieving certain aims.

2) Subpassionaries who themselves are not able to completely adapt the social system. That is why they need additional support, but can be easily mobilized into the revolutionary actions under direction of passioners.

Revolutionary changes led by passioners are possible to occur if a situation of total instability has developed or in case if the existing institutional set-up is been reforming, and the process of reforming is accompanied with a high degree of dissatisfaction in a society.

The quantity of subpassionaries raises when general ethnic activity, which also could be called "common identity basis" reduces. The share of this group can be compared with entropy-eroding cornerstones of an existing system, which gives passionaries chances to improve the system more easily.

Passionaries, playing role of so called "energy bombs", attract and direct activity in other people with greater energy and, eventually, in "normal" people with lower energy as well. According to results of survey passionarians who are active creators of history make up a small part of society $-3-5 \%$ [10, p. 59].

The decline in the overall level of passionarity of the system, associated with a decrease in the number of passionaries, leads to the fact that in the main areas of public administration (politics, the army, the civil service, ideological institutions, and so on), the so-called "harmonious individuals" begin to dominate, whose passion impulse is equal in magnitude to the impulse of the instinct of self-preservation, or sub-passionaries, whose passion impulse is less than the impulse of the instinct of self-preservation. These types of personality begin to occupy vacant managerial positions due to the lack of passionaries with the help of family ties and the system of clannishness, which is very common in Russia. This tendency of these "new people" in management creates new patterns of behavior, which leads to the simplification of the public administration system and the inhibition of its development, taking into account the needs of society.

If we try to classify different types of passionarity according to its orientation, we can distinguish two key types as regards the criterion of constructiveness and destructiveness of passion activity: adequate passionarity and «shadow» passionarity.

Adequate passionarity is manifested in the high activity of the individual to achieve goals that contribute to his self-actualization, spiritual and personal development [11]. Even if the passionary deliberately sacrifices one area of his life in the name of embodying the idea of another area of his life (for example, refusing to start a family because of complete immersion in a profession or going to a monastery in the name of 
spiritual goals, etc.) - as long as such actions do not have a clear destructive impact on the personality of the passionary this will be considered a manifestation of adequate passionarity.

Shadow passionarity is shown in the implementation of ideas connected with destructive and self-destructive actions. Fortunately, shadowy passionaries are less common in society: usually, a person who is prone to antisocial and immoral behavior does not have a clearly expressed "idea of evil" and not inclined to show a strong will of gathering people around the idea.

It raises the question about defining and measuring the qualities by which we can choose passionaries or subpassionaries. As far as we can describe passionarity as a complex of socially and economic valuable features allowing person to increase useful for the society and the enterprise abilities, it could be reasonable to mention among such features the following ones:

Strong-willed qualities. The theory of passionarity characterizes a passionate person with a "long will". And although the goal often remains illusory, a passionate person under the influence of an irresistible desire for activity, easily overcomes any obstacles that are encountered on the way to achieving his plan, finds ways and means to achieve the goal.

Adaptability. A passionate person is capable of conquering new areas, developing them. Therefore, he or she has a high level of adaptation to new conditions, as well as the ability to change conditions for himself, improving the new environment. Its ability to adapt is assessed as overadaptation.

Sacrifice. Passionate leaders lead a bright but short life; they are often diagnosed with an inclination to take risks, low level of value in their own lives, combined with an experience of passion and impulsivity.

Aggressiveness. The passionary theory in some sources is called the theory of aggression, because associated with the conquest of territories, with the conduct of wars and revolutions.

\section{Conclusion}

Leaders have always were key figures in changing a society. Revolutionary changes need charismatic leaders - so-called passioners. Only such type of people is able and has a strong desire to lead crowds to new achievements and to direct people and institutions to changes. Leaders, not managers, implement changes in politics and business. The success if their ideas depends on their ability to create new teams as well as on the managerial process to leverage and add substance to their visions and energy. Passionarity manifestation of the leaders as the ability of a personality to change the environment and themselves, the need to overcome difficulties. Passionarity is a dynamic feature of the psyche that occurs as a result of passionarity push, and forms a certain number of people, within the population, who tend to act.

Today in the world and, in particular, in Russia, the so-called "creative class" is being formed, consisting of people involved in solving important technical, innovative, scientific and other tasks based on independent thinking, creative abilities and a high level of education. This is a special rational type of people for whom knowledge, individual characteristics and personal merits (career) are important.

Development of activity as internal energy is possible on condition that there is imagination, creativity and courage, self-confidence, self-reliance, purposefulness and ability to prove own opinions.

In terms of management passionarity means a set of personality qualities that provide an active life position of the person. Passionarity is a characterological dominant, an irresistible inner desire (drive) (conscious or, more often, unconscious) of activities aimed at achieving a certain aim (often illusory).

Management based on a high level of performance discipline in the creation of goods and services is the foundation of a traditional organization. In contrast to this form of management, the model of passionate leadership, based on highly developed leadership capital and characterized by a relevant "leadership network", is now beginning to prevail in more promising selflearning organizations.

To overcome this tendency of the gap between the priorities of public power and the needs of society, passionarity is needed, which allows managers to rise above their personal interests. Passionarity will give an impetus to new tools and methods of management, that is, the preservation and development of the nation.

In the context of public administration, it is passionarity that provides the "beneficiary" (the state) with the implementation of their tasks by involving human capital in the management process. With regard to the applicability of the passionary management style in Russia, socio-cultural factors and especially the morphology of passionarity need careful empirical testing in relation to specific socio-structural and socioterritorial conditions.

The most actual problems for public management today are creativity, team building, facilitation and moderation, transformation of beliefs, emotional competence, leadership, etc. Passionarity becomes the driving force in achieving the public management goals, a positive change in the aggregate state of the internal environment. This becomes the key to success.

The need for passionaries gives rise to the question are passionaries born or become? In what way is passionarity formed?

The assumption that passionarity is inherited has not been scientifically proven, but the fact that it is contagious is known and proven. Thus, ordinary citizens who are in proximity to any epicenter begin to behave as passionary ones. If a person goes away for a certain distance, they behave again as usual. This phenomenon is called passionary induction and is actively used by experts. Obviously, the first two ways have nothing to do with upbringing. Passionary induction will be understood as changes in the mood and behavior of people in the presence of more passionary individuals. Consequently, such a property of passionary personality as passionary induction can be recognized as the key one. 


\section{References}

1. L. Puzyrevsky, Bulletin of the St. Petersburg University of the Ministry of Internal Affairs of Russia, 4 (60), 2013.

2. O. Glushakova, Public management of the processes of ensuring the quality of life in socioeconomic systems (Pub. House of the Siberian Academy of Finance and Banking, Novosibirsk, 2016)

3. N. Havrysh, K. Krytiy, Development trends in pedagogical and psychological sciences: the experience of countries of Eastern Europe and prospects of Ukraine (Baltija Publishing, Riga, 2018)

4. Yu. Karpovich, Proceedings of the XIX AllRussian Scientific and Practical Conference with International Participation (2020)

5. L. Gumilev, Ethnogenesis and the Earth's biosphere (Azbuka-klastika, St. Petersburg, 2002)

6. V. Nikishkin. Practical marketing, 1, 95 (2005)

7. R. Kheifets, D. Lauri, Work of the leader. Leadership. (Alpina Business Books, Moscow, 2006).

8. Yu. Podkorytov, G. Vinokurov, Strategic stability, 2 (43) (2008)

9. A. Vladimirov, Beachhead, 4-5 (2015)

10. Y. Zymyna, Pedahohycheskoe obrazovanye, 1 (2007)

11. N. Vyunova, M. Larskikh, I. Strebkova, Vestnik VSTU, 3-2 (2014). 